\title{
Correction to: Big data and business analytics ecosystems: paving the way towards digital transformation and sustainable societies
}

\author{
Ilias O. Pappas ${ }^{1} \cdot$ Patrick Mikalef $^{1} \cdot$ Michail N. Giannakos $^{1} \cdot$ John Krogstie $^{1}$. \\ George Lekakos ${ }^{2}$
}

Published online: 4 October 2021

(c) Springer-Verlag GmbH Germany, part of Springer Nature 2021

\section{Correction to: Information Systems and e-Business Management (2018) 16:479-491 https://doi.org/10.1007/s10257-018-0377-z}

In the original publication, the agreement Number "751550" in the last line of the "Acknowledgements" section is incorrect.

The correct agreement number is "751510".

Publisher's Note Springer Nature remains neutral with regard to jurisdictional claims in published maps and institutional affiliations.

The original article can be found online at https://doi.org/10.1007/s10257-018-0377-z.

Ilias O. Pappas

ilpappas@ntnu.no

Patrick Mikalef

patrick.mikalef@ntnu.no

Michail N. Giannakos

michailg@ntnu.no

John Krogstie

john.krogstie@ntnu.no

George Lekakos

glekakos@aueb.gr

1 Department of Computer Science, Norwegian University of Science and Technology (NTNU), Sem Sælands vei 7-9, 7491 Trondheim, Norway

2 Department of Management Science and Technology, Athens University of Economics and Business, Patission Str. 76, 10434 Athens, Greece 